\title{
A Case of Collateral Circulation Between the Portal and Systemic Veins through the Left Para-umbilical and Left Inferior Epigastric Veins in Man
}

\author{
By
}

\author{
Kinziro Kubota, Isoo Noguchi,* Masuo Narita,* \\ Takeo Nakano* and Ryoichi Nakagawa* \\ Department of Anatomy, Tokyo Medical and Dental University, Tokyo
}

It has been described in a great number of books that a paraumbilical vein often becomes an important collateral pathway when the circulation in liver is, for any reason, obstructed. There is, however, no paper giving a detailed anatomical description of a well developed para-umbilical vein.

The authors in this paper have found a case of such collateral circulation in the body (ca. 50-year-old man) in the dissection room.

\section{Macroscopic Appearance}

When the lower part of the left rectus muscle was removed to observe the posterior wall of the sheath of rectus abdominis, a very large vein composed of a membranous wall was seen (Fig. 1). By careful dissection, this vein was accompanied with a small artery and was regarded as the left inferior epigastric vein.

The vein perforates the posterior wall of the rectus sheath at the level of the umbilicus and then runs upwards to the inferior ridge of the liver with the chorda v. umbilicalis and other small blood vessels in the ventral mesohepaticum. It communicates with the chorda about $4 \mathrm{~cm}$. caudal of the porta hepatis (Fig. 2).

Furthermore, as shown in Fig. 2, a small vein and an artery were found in the ventral mesohepaticum; the vein and artery communicate

\footnotetext{
* Students of the Tokyo Med. and Dent. University.
} 
respectively with the small branches of the right inferior epigastric vessels at the level of the umbilicus and the small vein enters into the obliterated umbilical vein. Judging from these topographic appearances, both veins, large and small, should be regarded as the para-umbilical - veins.

The liver is very flat, but nearly normal in transverse dimension. Its weight is very light, apparently below the half of the normal value. It was, however, not submitted to weighing because of the foregoing dissection in situ. The portal vein is remarkably dilated. Especially, the right branch is of an elongated sac-like shape, from which numerous interlobular branches arise. The remarkably dilated sac-like right branch of the portal vein links to the inferior vena cava with a short fibrous tissue which may be regarded as a part of the ligamentum venosum (Fig. 3).

\section{Microscopic Appearance}

When a collateral circulation is established, it is of interest to note the histoarchitectural structure of their walls. So materials from various parts of the wall of this collateral vein were examined under microscope. Embedding in paraffin, staining with H-E, Mason-Goldner's and Gomori's methods.

In general, the wall of the vein is very thin. The collagenous tissue is present in much larger amount, but the elastic element is poor. The smooth muscle fibers are very sparse and in some parts even lacking (Figs. 4 and 5).

A histological examination of the liver shows that the interlobular connective tissue is relatively sparse and the lobular investment is not so complete. The lobules are cylindrical or irregularly polyhedral in shape. The parenchym-cells tend to be arranged in a radiating direction around the central vein of the lobule. The liver seems to show histologically no general aspect of cirrhosis.

\section{References}

1) Johnston, T.B. \& Whillis, J. (1949): The portal system of veins. Gray's Anatomy, 30th Edition, Lond., New York \& Toronto.

2) Kop s h, Fr. (1955): Vena portas. Rauber-Kopsch Lehrbuch u. Atlas der Anatomie des Menschen, Bd. 1, Stuttgart.

3) Na it o, E. (1931): Die Vene der Brust- u. Bauchwand der Japaner. Archiv für Japanische Chirurgie, Bd. 8. (Japanes3).

4) Schaeffer, J.P. (1942): The portal vein. Mo:ris' Human Anatomy, 1lth Edition, New York \& Toronto. 
Plate I

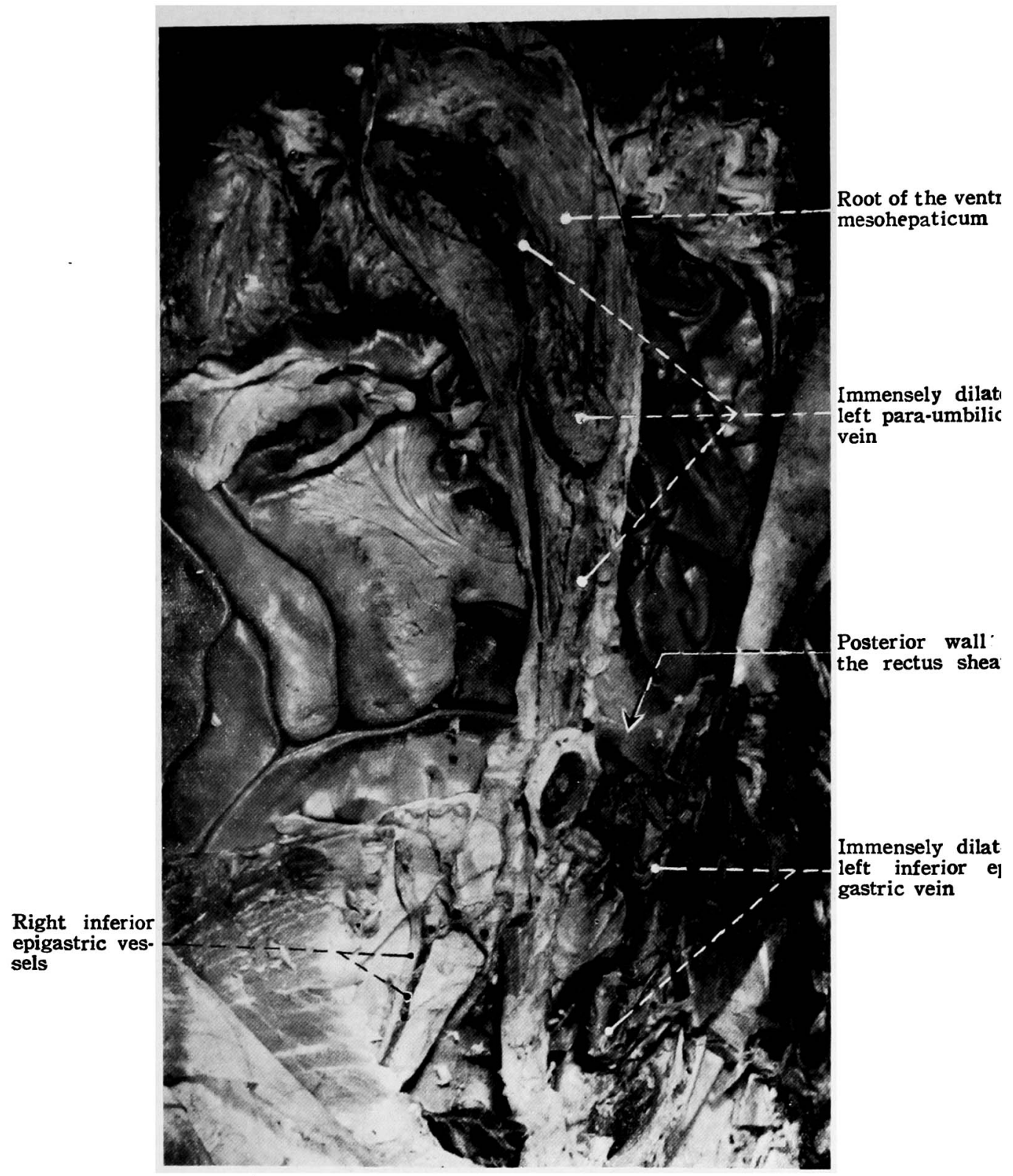

Fig. 1. A photograph showing a collateral pathway between the portal vein and left external iliac vein. (Ventral view of abdomen) 


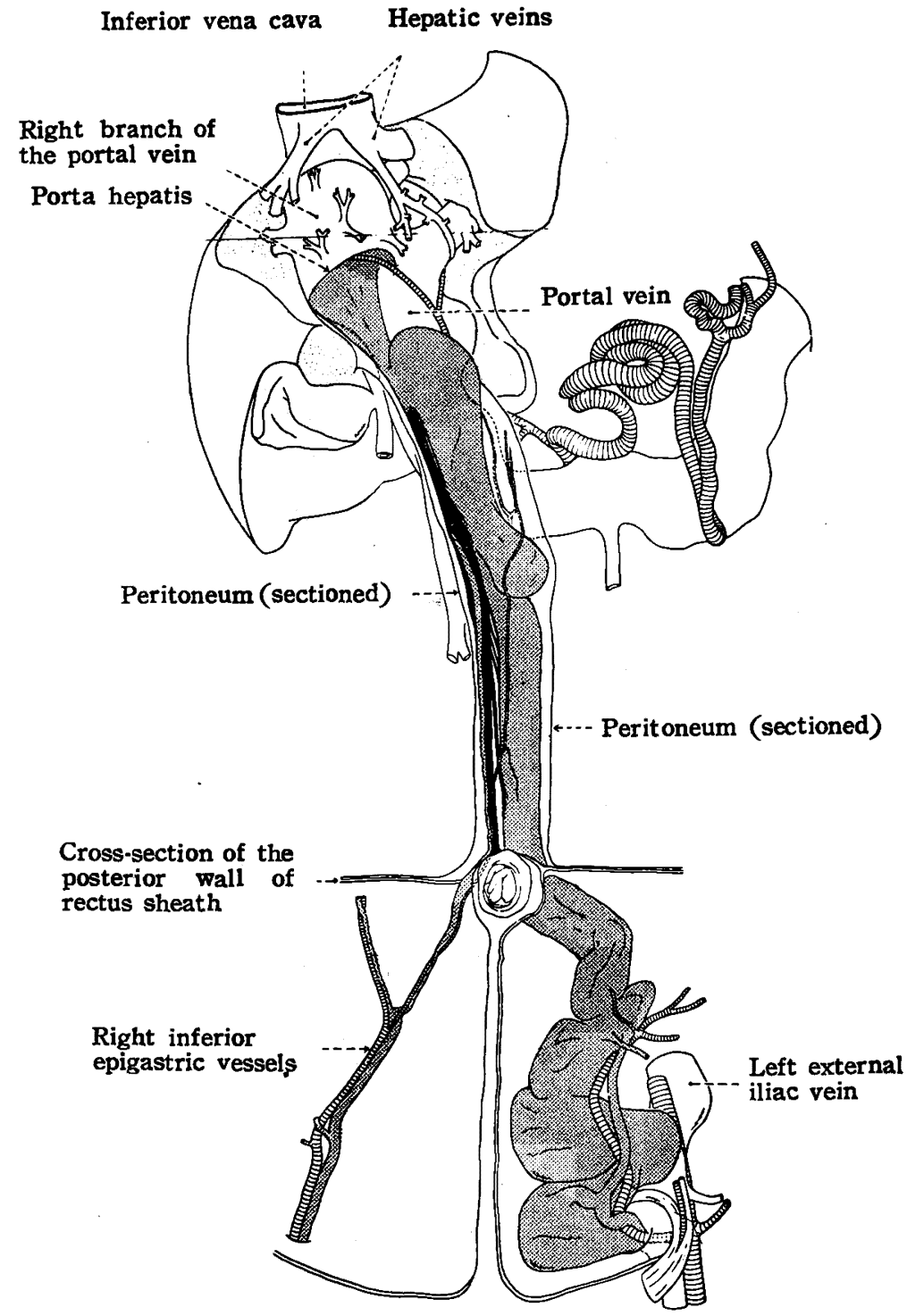

Fig. 2. Drawing of section photographed in Fig. 1, traced in natural size and reduced to $1 / 3$. The collateral pathway is found on the left and the para-umbilical and inferior epigastric veins on the right (they are all shadowed). The obliterated fibrous part of the chorda v. umbilicalis is blackened. 


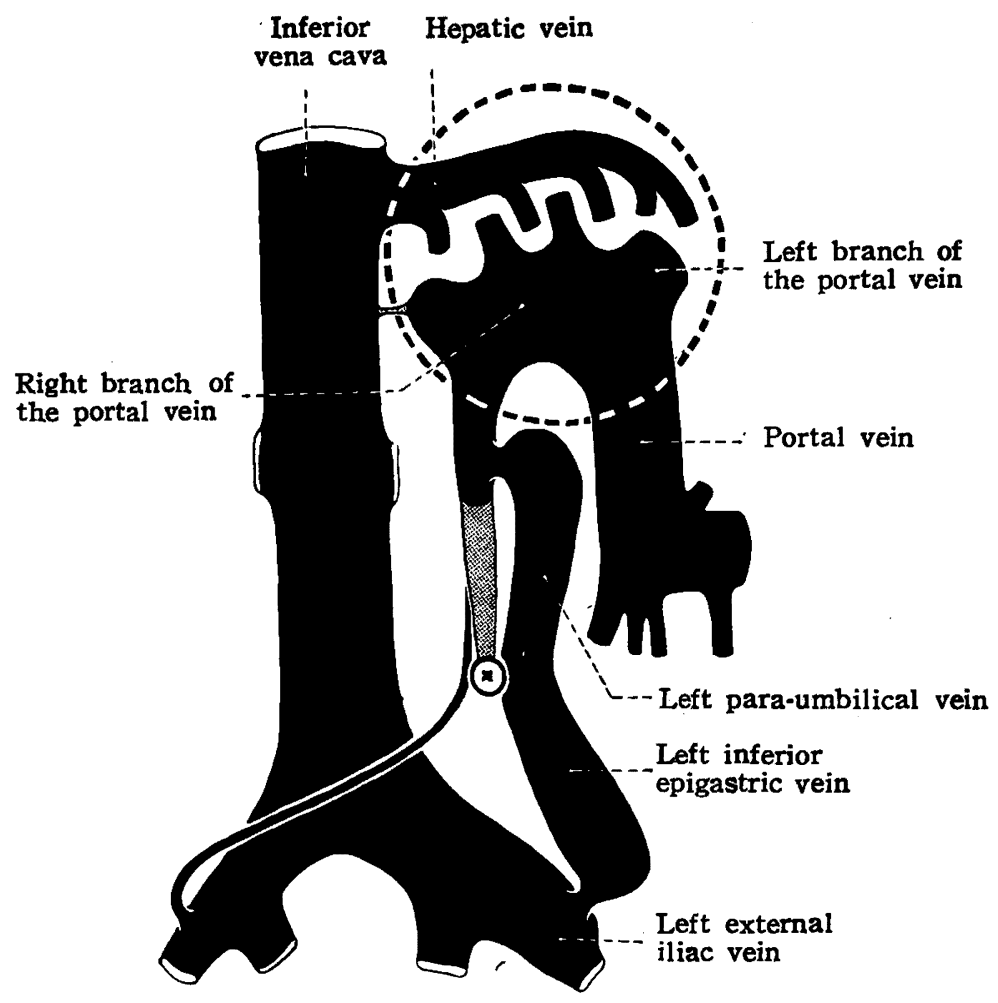

Fig. 3. Diagram showing the relation between the collateral circulation and the other circulations. The dotted-line-circle shows the venous system in the liver. The obliterated parts of the chorda v. umbilicais and the chorda ductus venosi are shadowed. All of the blood pathway is blackened. 


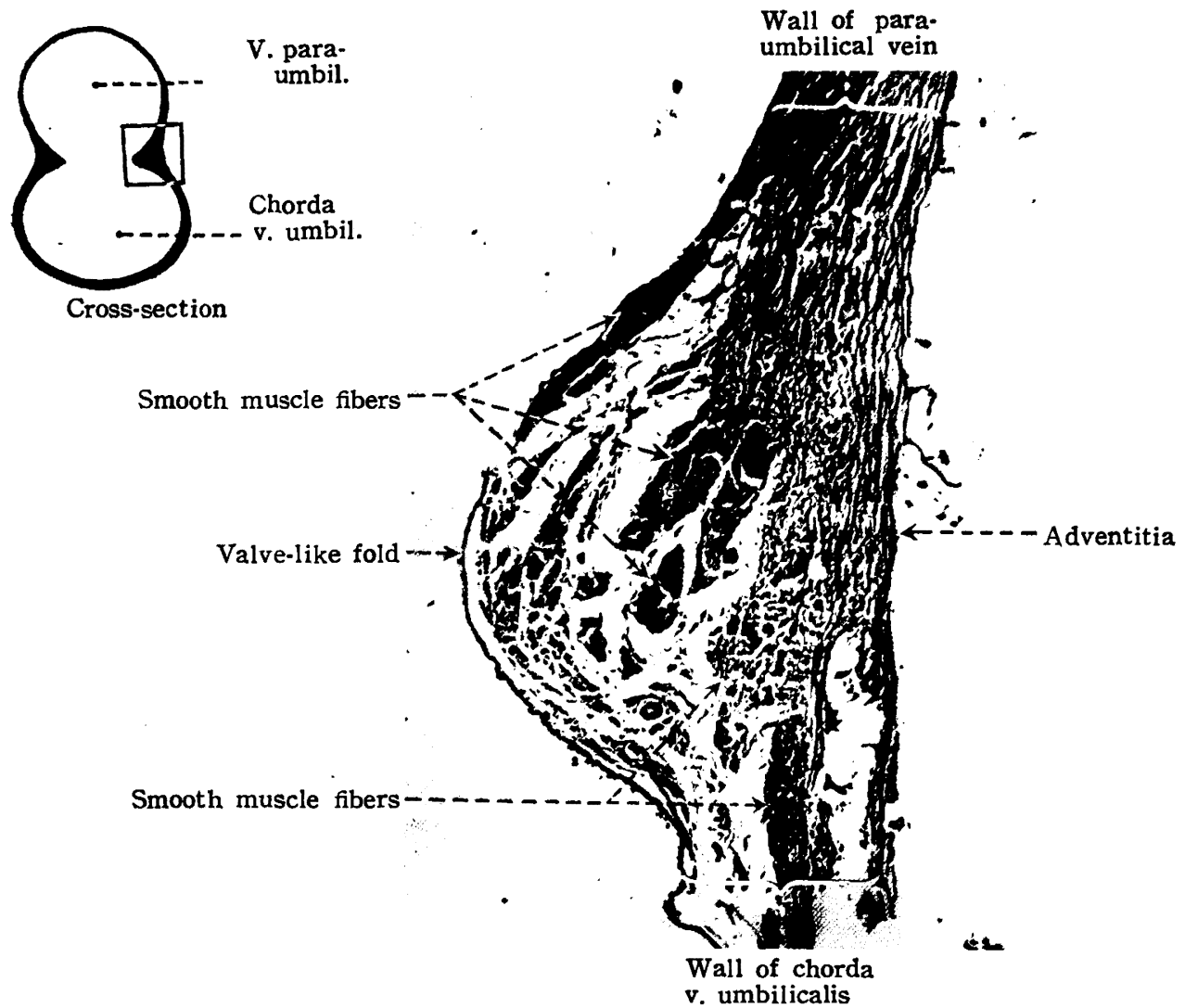

Fig. 4. A photomicrograph of the wall where the left para-umbilical vein communicates with the non-obliterated part of the chorda $v$. umbilicalis. The smooth muscles arranged irregularly are seen. H-E stain. $\times 50$ 


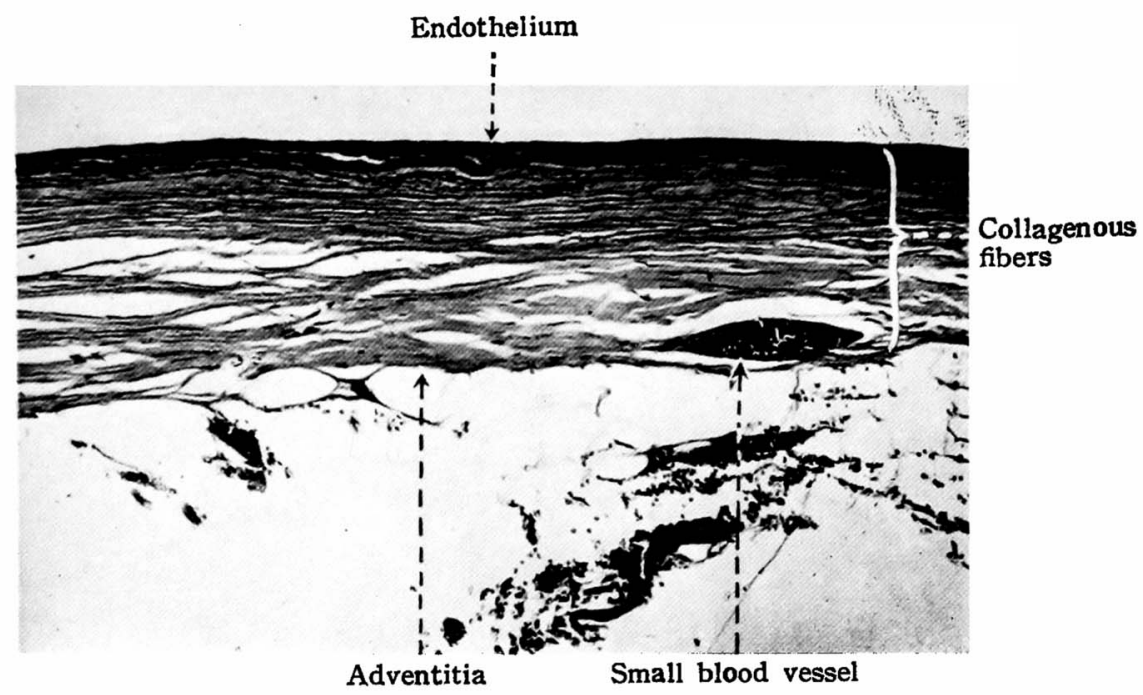

Fig. 5. A photomicrograph of the wall of the collateral pathway in which no smooth muscle is seen. H-E stain. $\times 100$ 